\title{
Autoimmune Diseases and Acquired Von Willebrand Disease in Two Cases of Progeria
}

\author{
Monem Makki Alshok \\ Department of Medicine, College of Medicine, University of Babylon, Babylon, Iraq \\ Email:dr_monem_alshok@yahoo.com
}

Received 24 September 2014; revised 12 October 2014; accepted 9 November 2014

Copyright (C) 2014 by author and Scientific Research Publishing Inc.

This work is licensed under the Creative Commons Attribution International License (CC BY). http://creativecommons.org/licenses/by/4.0/

(c) (i) Open Access

\begin{abstract}
Ammar A., a 23-year-old male patient, who lives in Babylon, Haswa District, and his mother describes symptoms of growth retardation, skin changes, hair changes early graying and alopecia. These manifestation started early during his childhood period. There is canseguanity between the patient's mother \& father also one of the patient's sister has similar illness and one male brother died few months following his birth. We admit the patient to hospital due acute pulmonary infection in Jan 2009, which is controlled after a course of antibiotic and after 5 months he develops generalised mucocuteneous bullous eruption which shows partial response to oral prednisolone 2 $\mathrm{mg} / \mathrm{Kg}$. The patient has normal IQ and he is in the secondary school and he has normal blood picture and the only abnormal biochemical abnormalities is mild hyperlipidemia Serum cholestrol of $5.8 \mathrm{mmol} / \mathrm{L}$ and Serum Triglyceride of $260 \mathrm{mg} / \mathrm{dl}$. Ammar's Sister Qawthar A., who has a similar phenotypic manifestations, presented skin vitiligo and hepatosplenomegaly associated with sever anemia and jaundice and her presentation suggestive of autoimmune haemolytic anemia improved following blood transfusion, corticosteroid and azothioprim. In February 2014 Ammer presented with multiple and diffuse cuteneous ecchymymosis with markedly prolonged PTT and slightly proloned bleeding time highly consistent with acquired Von Willebrand's disease. In conclusion premature aging is a predisposing factor for disturbed immunity and development of autoimmune diseases.
\end{abstract}

\section{Keywords}

Progeria, Autoimmune Diseases, Pemphigus, Autoimmune Hemolytic Anemia, Acquired Von Willebrand Disease

\section{Introduction}

Progeria affects approximately one out of every eight million children, with only a few hundred cases seen 
worldwide. Signs usually first develop between the age of 6 and 12 months, though the disease occasionally does not develop until 2 years of age or later [1]. Nearly $97 \%$ of all children with the disease are Caucasian, and slightly more males than females develop the disease. Children with progeria appear perfectly healthy at birth. Typically, the first signs of the disease appear between 6 and 12 months when the child fails to gain weight and his/her skin starts to become thick and inelastic, particularly on the arms, legs, and hips. Scalp hair and eyelashes are then progressively lost, usually progressing to complete baldness. At about the same time, much of the body's fat is lost. As a result of this loss of hair and subcutaneous fat, many of the body's veins become prominent, particularly those on the scalp. Children with progeria usually will also not grow to a full height, will develop thin limbs with prominent joints, and will have a small jaw (micrognathia). As the disease progresses, individuals with progeria develop widespread thickening and loss of elasticity of the artery walls, severe joint stiffness similar to that of arthritis, and frequent hip dislocations. A few children have been reported who have muscle weakness as well, and the disease is related to a form of muscular dystrophy. However, most children do not have muscle problems. Children with progeria have normal intellectual capabilities and can learn just as well as (if not better than) other children of their same age and also demonstrate the same range of emotions and feelings as other children. They do often remain very reserved in the presence of strangers, however, because they are aware very early on in life that they appear very different than their peers [2]. Progeria is caused by a change in the lamin A (LMNA) gene. This mutation causes the gene to make an abnormal form of the lamin A protein. This abnormal protein seems to destabilize the membrane surrounding the nucleus of cells [3] [4]. It is thought that this loss of stability contributes to many of the symptoms of the disease. There seem to be several other genes that contribute to the symptoms of the disease, but these have not yet been identified. It is unclear at this point how exactly the changes in the lamin A lead to the typical disease symptoms. This change is not believed to be passed down from parent to child and is thought to occur at random. Nothing is known to cause the change in the gene, nor is anything known to prevent it. The present case demonstrates that progeria might be associated with different mucucuteneous manifestations and defects in the immunity [5].

\section{Case Report}

We presents Ammar Majid, a 21-year-old male patient, who lives in Babylon, Haswa District, and his mother describes symptoms of growth retardation, skin changes, hair changes early graying and alopecia. These manifestation started early during his childhood period. There is canseguanity between the patient's mother \& father also one of the patient's sister has similar illness and one male brother died few months following birth. Symptoms and signs become more evident within 2 years of their life and include: Growth failure, Craniofacial abnormalities, e.g. craniofacial disproportio micrognathia, beaked nose. Physical changes of aging, e.g. wrinkled skin, balding (evident in the present Figures 1-11).

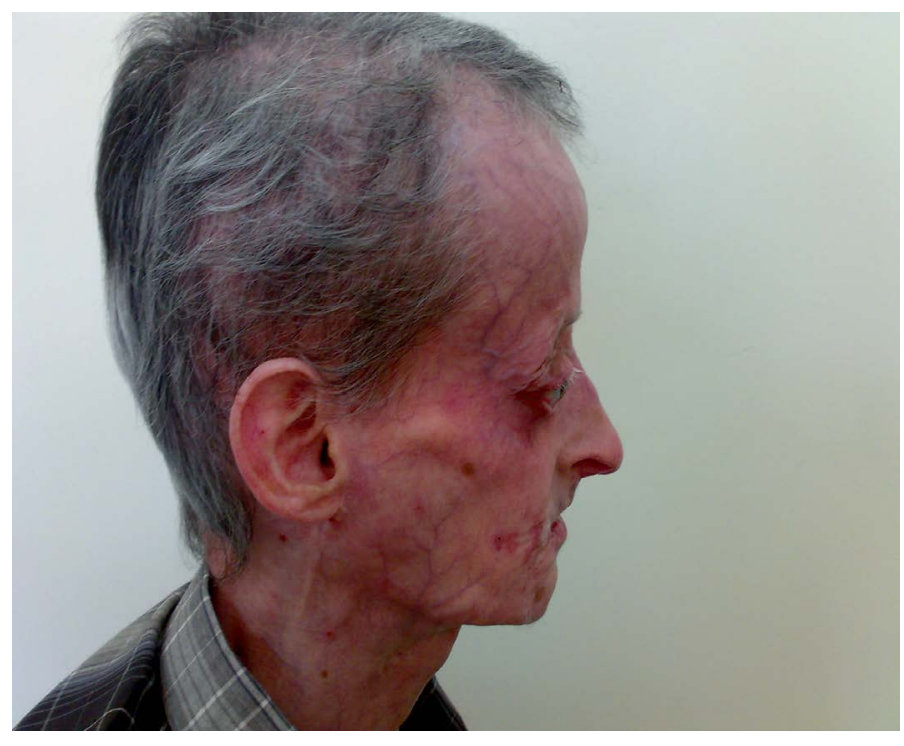

Figure 1. Facial appearance of Ammer age 23 years. 


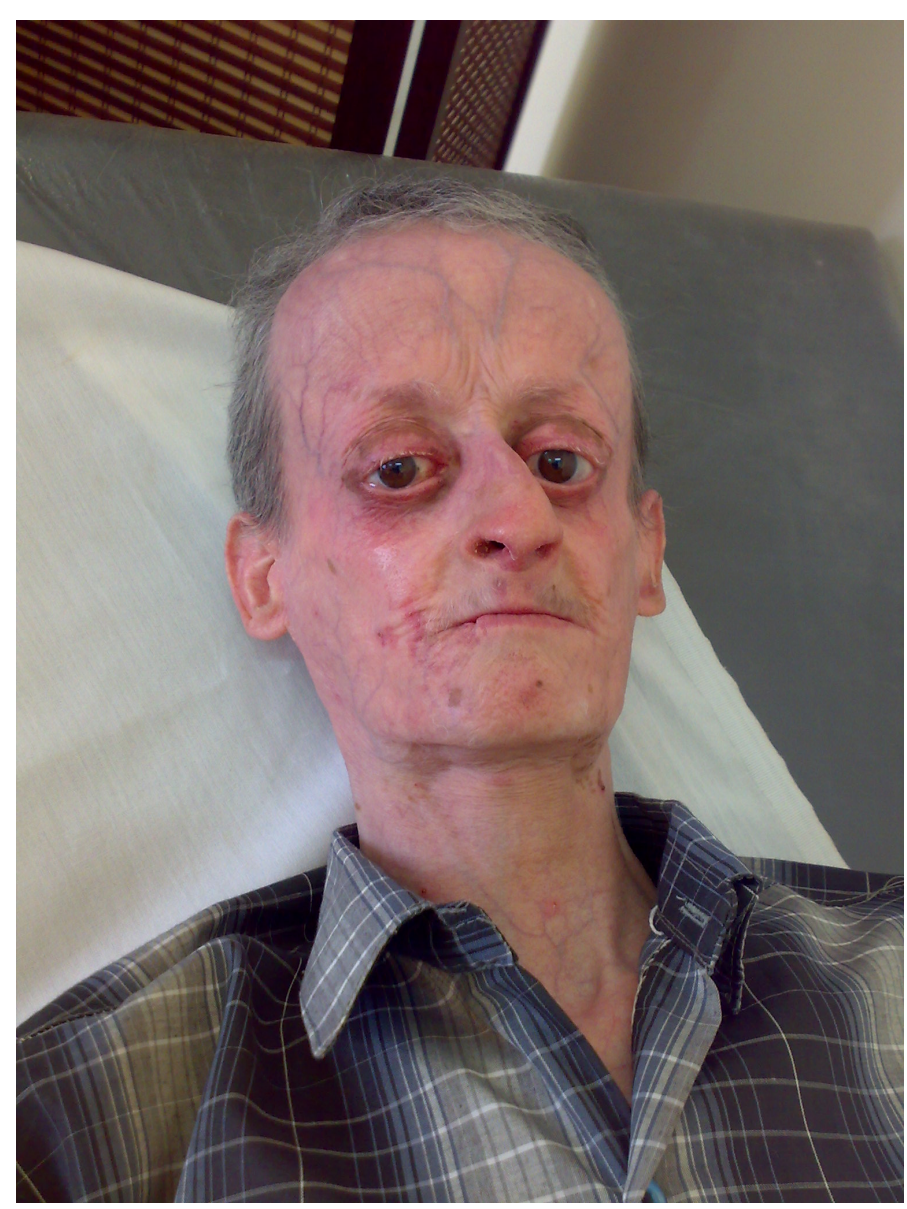

Figure 2. Ammar aged 23.

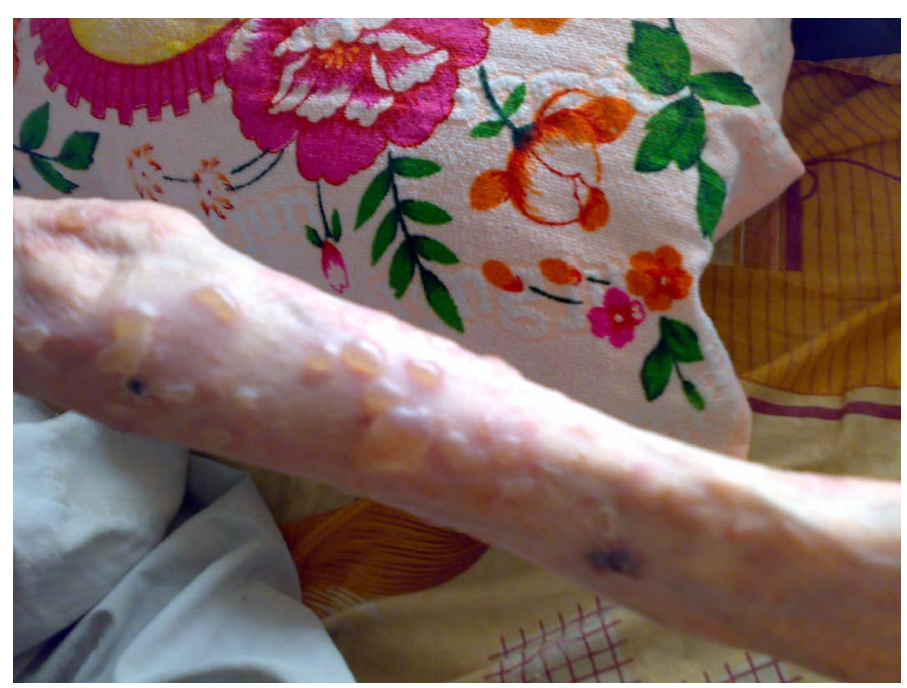

Figure 3. Skin pemphigus.

We admit the patient to hospital due acute and repeated pulmonary infections in January 2009, which is controlled after a course of antibiotic and after 5 months he develops generalised mucocuteneous bullous eruption which shows partial response to oral prednisolone $2 \mathrm{mg}$ per $\mathrm{Kg}$ and his sister also has vitiligo. The patient has normal IQ and he is in the secondary school and he has normal blood picture and the only abnormal biochemical ab- 


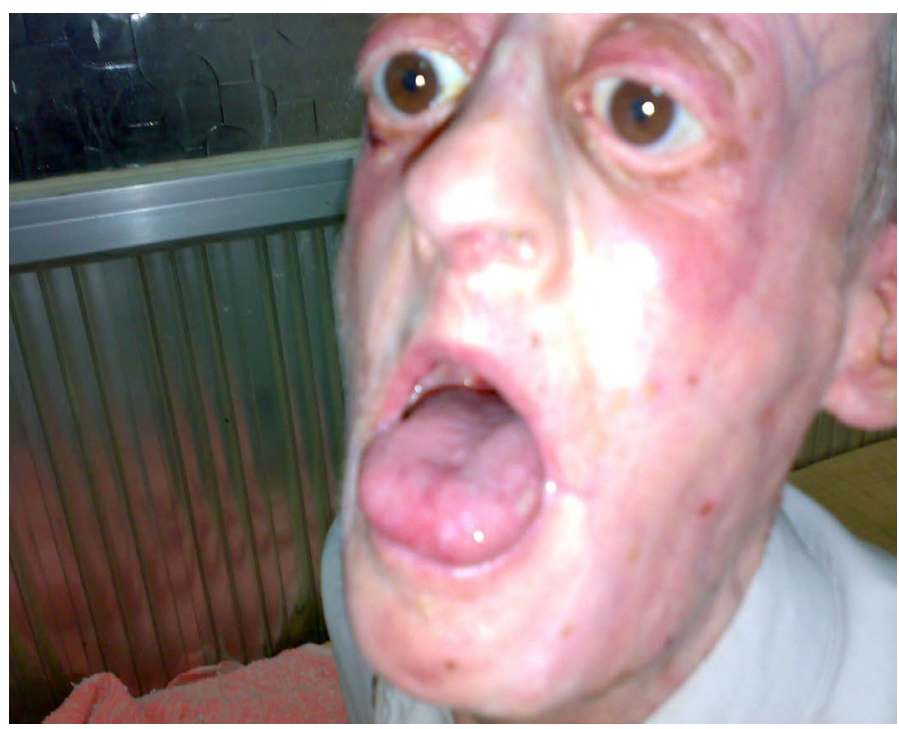

Figure 4. Oral ulcers.

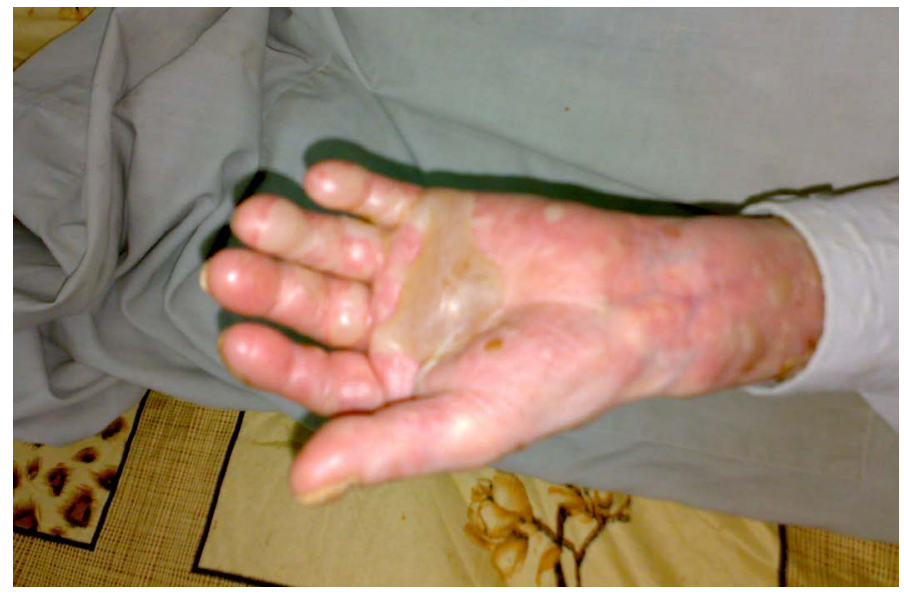

Figure 5. Big bullae.

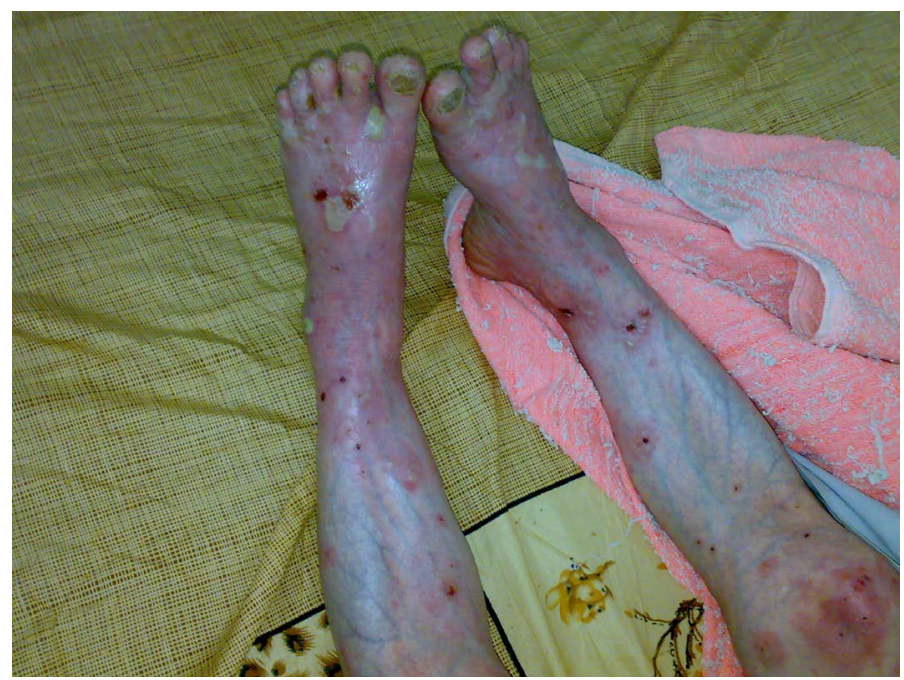

Figure 6. Skin change after therapy. 


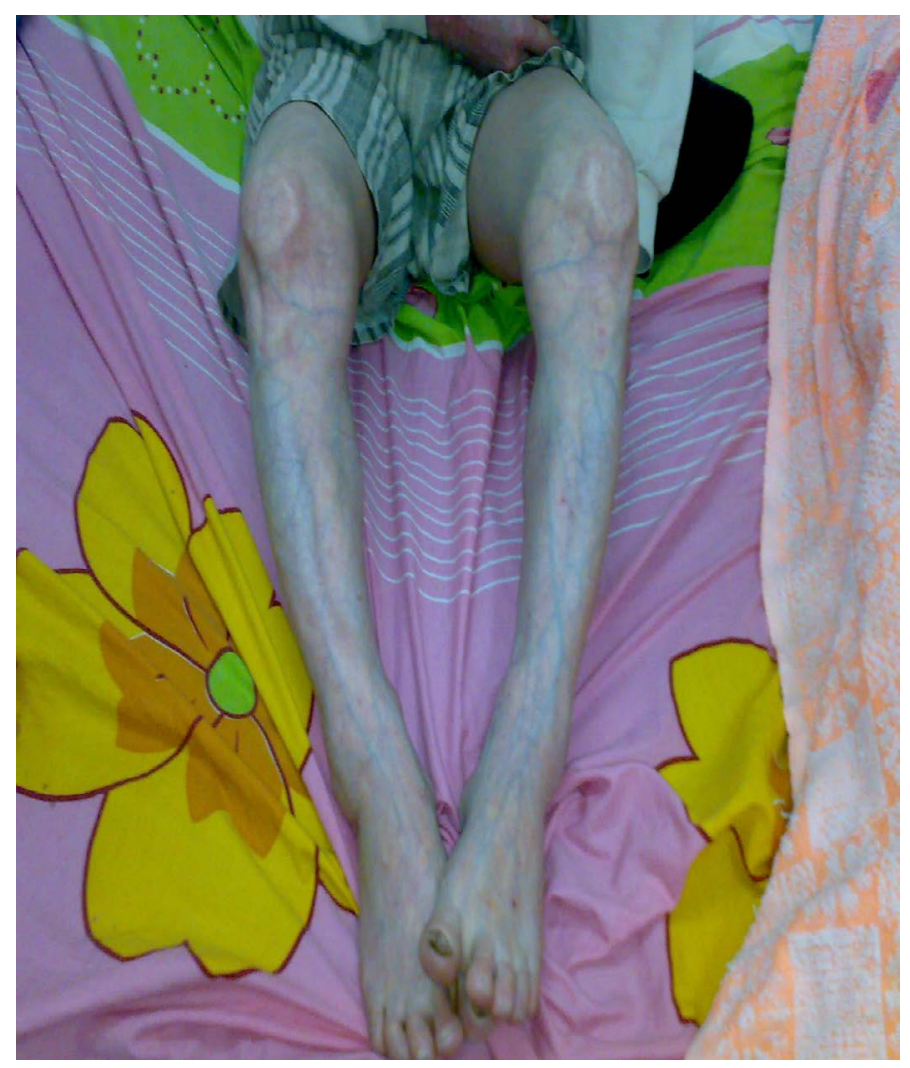

Figure 7. Skin before appearance of Bullae.

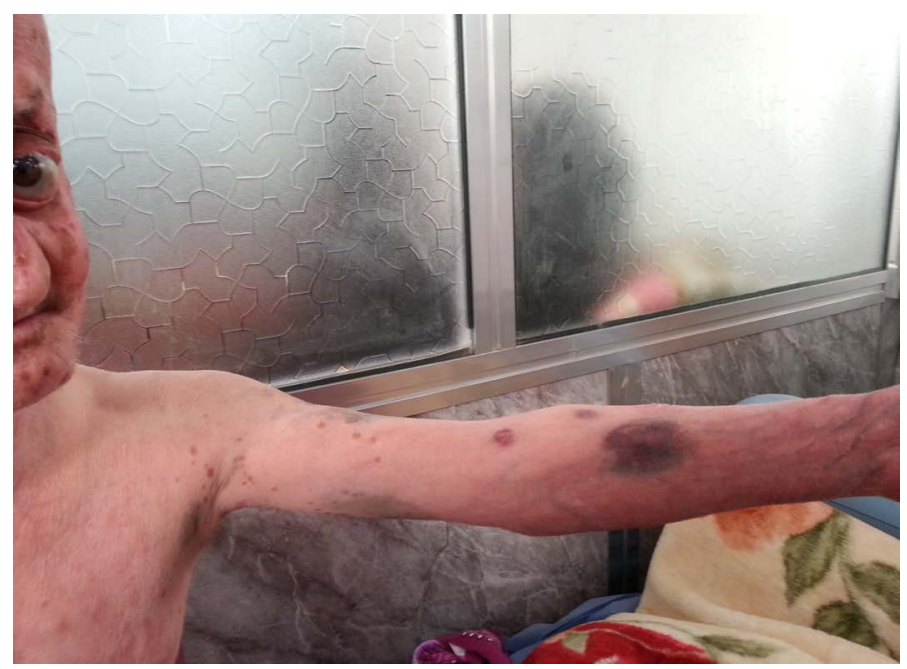

Figure 8. Large ecchymotic patches.

normalities is mild hyperlipidemia, Serum cholestrol of $5.8 \mathrm{mmol} / \mathrm{L}$ and Serum Triglyceride of $260 \mathrm{mg} / \mathrm{dl}$. CXR normal apart from signs of increased bronchial markings, ECG shows non-specific T wave changes. The patient is maintained on Aspirin $100 \mathrm{mg}$ per day, Simvastatine $20 \mathrm{mg}$ daily and prednisolone $10 \mathrm{mg}$ per day maintenance. We measures the changes in transaminase enzymes and electrolytes including calcium and phosphorous also some hormones including Growth hormone and thyroid function. The result of study demonstrate that there is mild decline in the basal GH level and with mild subclinical hypothyroidism with mild increase of TSH \& also the study demonstrate significant increase in lipid profile with progression of the disease with time in addition there is non-significant rising level of inorganic phosphates and calcium. 


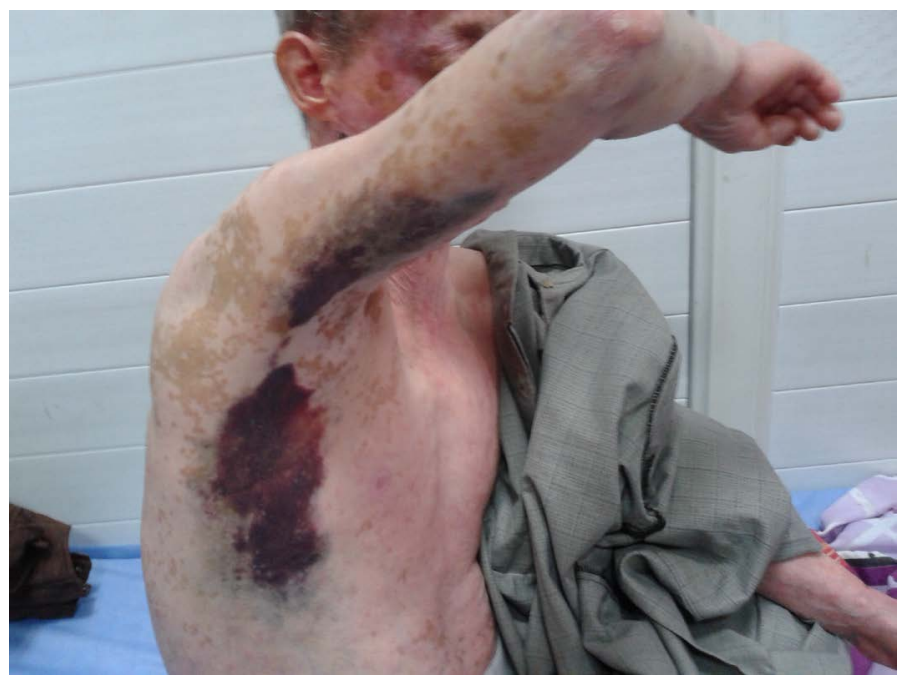

Figure 9. Large ecchymotic patches.

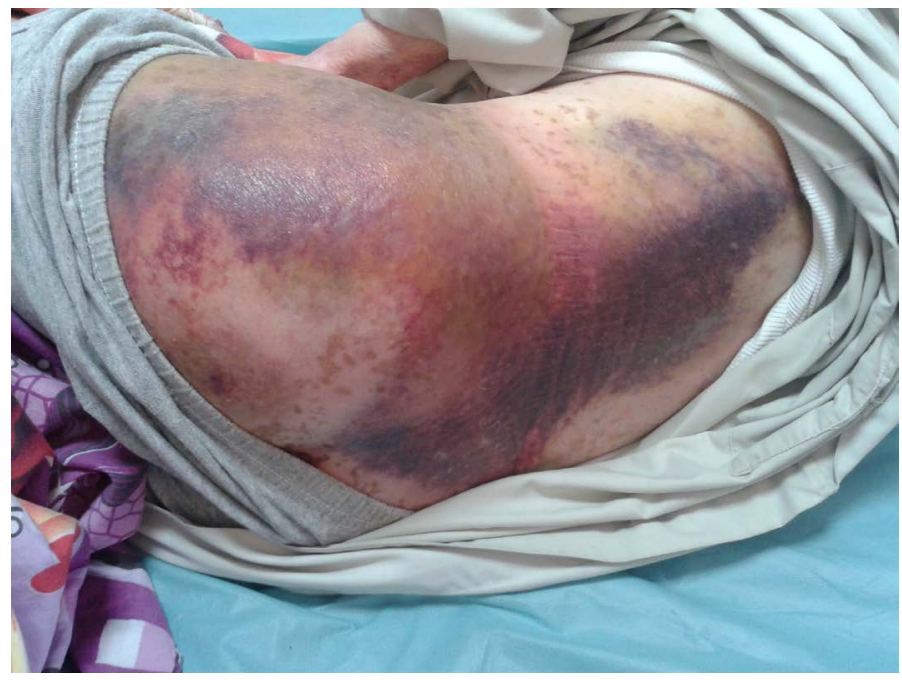

Figure 10. Large ecchymotic patches.

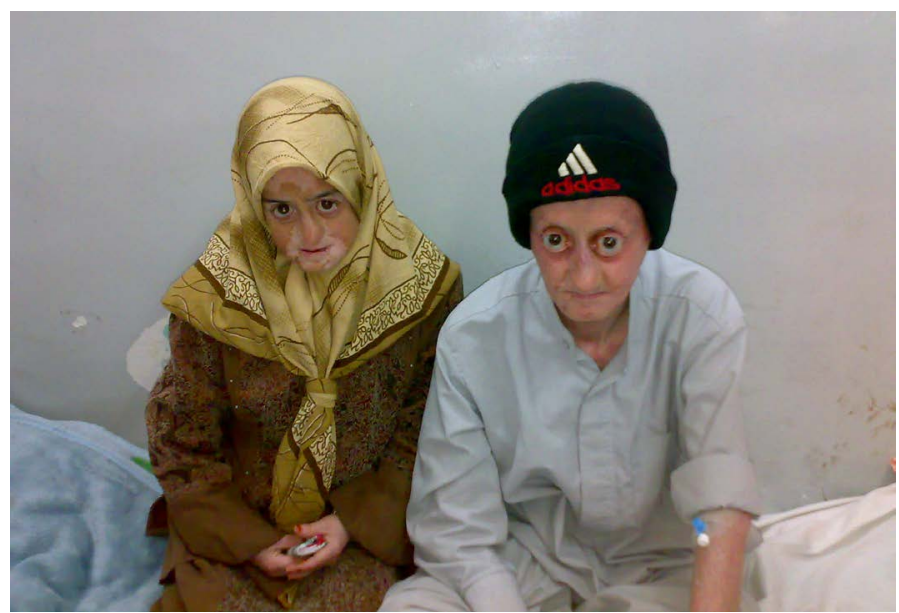

Figure 11. Ammar's sister Kawthur aged 14 years, died from sever autoimmune hemolytic Anemia. 
The molecular studies of the patients of genomic DNA isolated from white blood cells detecting Exon 11 of LMNA gene and mutation $1868 \mathrm{C}>\mathrm{G}$ in the patients and their mother. Ammar's sister aged 14 years presented with moderate anaemia, vitiligo and hepatosplemomegaly and her investigations were consistant with Coomb's positive autoimmune hemolytic anemia partially responding to maintance dose of $15 \mathrm{mg}$ prednisolone, $100 \mathrm{mg}$ azothioprine and supportive treatment including blood transfusion, but unfortunetly the patient died after 1 year of her presentation. During the year 2014 February, Ammar presented with several large ecchymotic patches all over his body with swelling and pain in his left leg, during this time his investigations demonstrate normal platelets count, mild normochromic anemia, Normal PT, Markedly prolonged PTT, normal circulating anticoagulants, reduced level of Factor VIII coagulant activity, slightly prolonged bleeding time.

\section{Discussion}

Muco cuteneous manifestations are common mode of presentation in Progeria, which is an extremely rare genetic disease that results in rapid aging, beginning early in childhood [6]. The main cuteneous manifestation described in our patient is Pemphigus and this indicates that these patients might be susceptible to certain autoimmune disorders due to a genetically induced immunological defects. In a study [5] done by Dr. Maria Eriksson's research team at the Karolinska Institutet in Sweden created a mouse model of Progeria with abnormalities of the skin and teeth. The mice are genetically engineered so that the Progeria mutation can be shut off at any time. Once disease was apparent, the gene for Progeria was turned off. After 13 weeks the skin was almost indistinguishable from normal skin. This study shows that in these tissues the expression of the Progeria mutation does not cause irreversible damage and that the reversal of disease is possible, which gives promise for treatment for Progeria. Another studies show that Progeria is reversible in the cardiovascular system and the skin of mouse models. The experiments were significant in not treating the mice until they expressed Progeria symptoms, whereas most previous studies began treatment before Progeria was apparent. Production of progerin (the damaging protein made from the Progeria gene) was inhibited either by treatment with a farnesyl transferase inhibitor (FTI) or by turning off the gene. In both cases the mice reverted to normal or almost normal conditions [7][9]. These observations provide encouraging evidence for the current clinical trial of FTIs for Progeria. Progerin is the abnormal protein causing Progeria. In recent years, several research groups have found that normal cells also produce progerin, but much less than the cells of a child with Progeria. A genetic test (Lamin A mutation) was recently developed that can test for and diagnosis progeria. Prior to the development of this test, the disease was diagnosed based solely on the physical symptoms \& signs. With the genetic test, children can be diagnosed at a much earlier age than they were before the test was available, allowing an earlier start to treatment. Also during differential diagnosis we should exclude segmental progerias (e.g., acrogeria, metageria) and other causes of growth failure. Premature aging is a feature of other rare progeroid syndromes, including: Werner's syndrome premature aging after puberty with hair thinning and development of conditions of old age (e.g., cataracts, diabetes, osteoporosis, atherosclerosis) and Rothmund-Thomson syndrome (premature aging with increased susceptibility to cancer). Both are caused by gene mutations leading to defective RecQ DNA helicases, which normally repair DNA. Cockayne's syndrome is an autosomal recessive disease caused by mutation in the 8ERCC gene which is important in DNA repair, clinical features include severe growth failure, cachectic appearance, retinopathy, hypertension, renal failure, skin photosensitivity, and intellectual disability. Neonatal progeroid (Wiedemann-Rautenstrauch) syndrome: is a recessively inherited syndrome of aging causing death by 2 years [3]. Other syndromes (e.g., Down, Ehlers-Danlos) occasionally have progeroid features [10]-[12]. Acquired VWD is usually associated with an underlying disorder, e.g. lymphoproliferative (48\%), cardiovascular (21\%), myeloproliferative (15\%), other neoplastic (5\%), and autoimmune disorders (2\%) are most frequent [13] [14]. In our case we demonstrate Acquired VWD in a case of progeria which reflects genetic and autoimmunity as an underlying mechanisms. From the above data we conclude that our patient is a real case of Progeria, which is a very rare genetic disorder, and we hope that future studies will reverse the genetic defect in this disorder.

\section{References}

[1] Debush, F.L. (1972) The HGP Syndrome. Report of 4 Cases and Review of Literature. The Journal of Pediatrics, 80, 697-724.

[2] Fossel, M. (2000) Human Aging and Progeria. Journal of Pediatric Endocrinology \& Metabolism, 13, $1477-1481$.

[3] Cao, H. and Hegle, R.A. (2003) LMNA Is Mutated in HGP Syndrome But Not in Wiedemann-Rautenstrauch Progeroid 
Syndrome. Journal of Human Genetics, 48, 271-274. http://dx.doi.org/10.1007/s10038-003-0025-3

[4] Rodriguez, S., Coppedè, F., Sagelius, H. and Erikson, M. (2009) Increased Expression of the Hutchinson-Gilford Progeria Syndrome Truncated Lamin A Transcript during Cell Aging. European Journal of Human Genetics, 1-10.

[5] Eriksson, et al. (2008) Reversible Phenotype in a Mouse Model of Hutchinson-Gilford Progeria Syndrome. Journal of Medical Genetics.

[6] Capell, B.S., Tlougan, B.E. and Orlow, S.J. (2009) From the Rarest to the Most Common: Insights from Progeroid Syndromes into Skin Cancer and Aging. Journal of Investigative Dermatology, 129, 2340-2350.

[7] Capell, et al. (2008) A Farnesyltransferase Inhibitor Prevents both the Onset and Late Progression of Cardiovascular Disease in a Progeria Mouse Model. Proceedings of the National Academy of Sciences, 105, 15902-15907.

[8] Rodriguez, S., Coppedè, F., Sagelius, H. and Erikson, M. (2009) Increased Expression of the Hutchinson-Gilford Progeria Syndrome Truncated Lamin A Transcript during Cell Aging. European Journal of Human Genetics, 17, 928-937. http://dx.doi.org/10.1038/ejhg.2008.270

[9] Fong, L.G., Vickers, T.A., Farber, E.A., Choi, C., Yun, U.J., Hu, Y., Yang, S.H., Coffinier, C., Lee, R., Yin, L., Davies, B.S., Andres, D.A., Spielmann, H.P., Bennett, C.F. and Young, S.G. (2009) Activating the Synthesis of Progerin, the Mutant Prelamin A in Hutchinson-Gilford Progeria Syndrome, with Antisense Oligonucleotides. Human Molecular Genetics, 18, 2462-2471. http://dx.doi.org/10.1093/hmg/ddp184

[10] Busch, A., Kiel, T., Heupel, W.M., Wehnert, M. and Huebner, S. (2009) Nuclear Protein Import Is Reduced in Cells Expressing Nuclear Envelopathy-Causing Lamin A Mutants. Experimental Cell Research, 315, 2373-2385. http://dx.doi.org/10.1016/j.yexcr.2009.05.003

[11] Kaiser, H.W. and Hanfland, J. (2002) eMedicine: Hutchinson-Gilford Progeria.

[12] Brown, W.T., Gordon, L.B. and Collins, F.S. (2003) Hutchinson-Gilford Syndrome. http://www.emedicine/com/derm/topic731.htm

[13] Federici, A.B., Rand, J.H., Bucciarelli, P., et al. (2000) Acquired Von Willebrand Syndrome: Data from an International Registry. Thrombosis and Haemostasis, 84, 345-349.

[14] Nichols, W.L., Rick, M.E., Ortel, T.L., et al. (2009) Clinical and Laboratory Diagnosis of Von Willebrand Disease: A Synopsis of the 2008 NHLBI/National Institutes of Health guidelines. American Journal of Hematology, 84, 366-370. http://dx.doi.org/10.1002/ajh.21405 
Scientific Research Publishing (SCIRP) is one of the largest Open Access journal publishers. It is currently publishing more than 200 open access, online, peer-reviewed journals covering a wide range of academic disciplines. SCIRP serves the worldwide academic communities and contributes to the progress and application of science with its publication.

Other selected journals from SCIRP are listed as below. Submit your manuscript to us via either submit@scirp.org or Online Submission Portal.
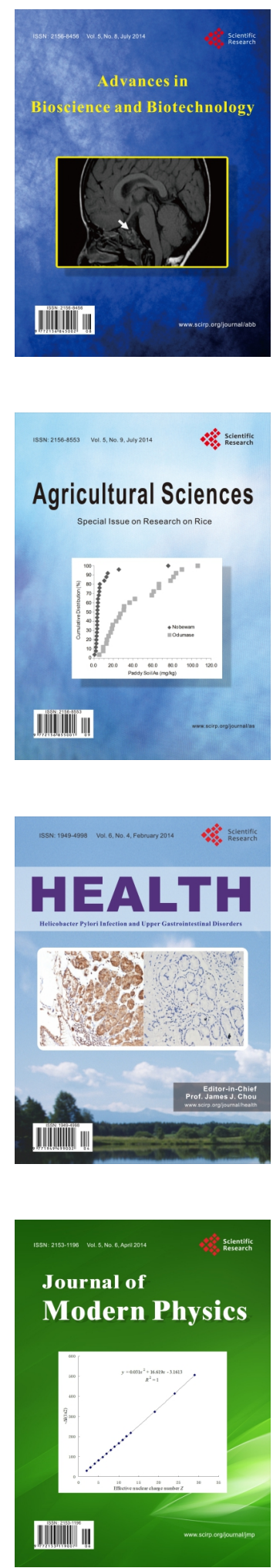
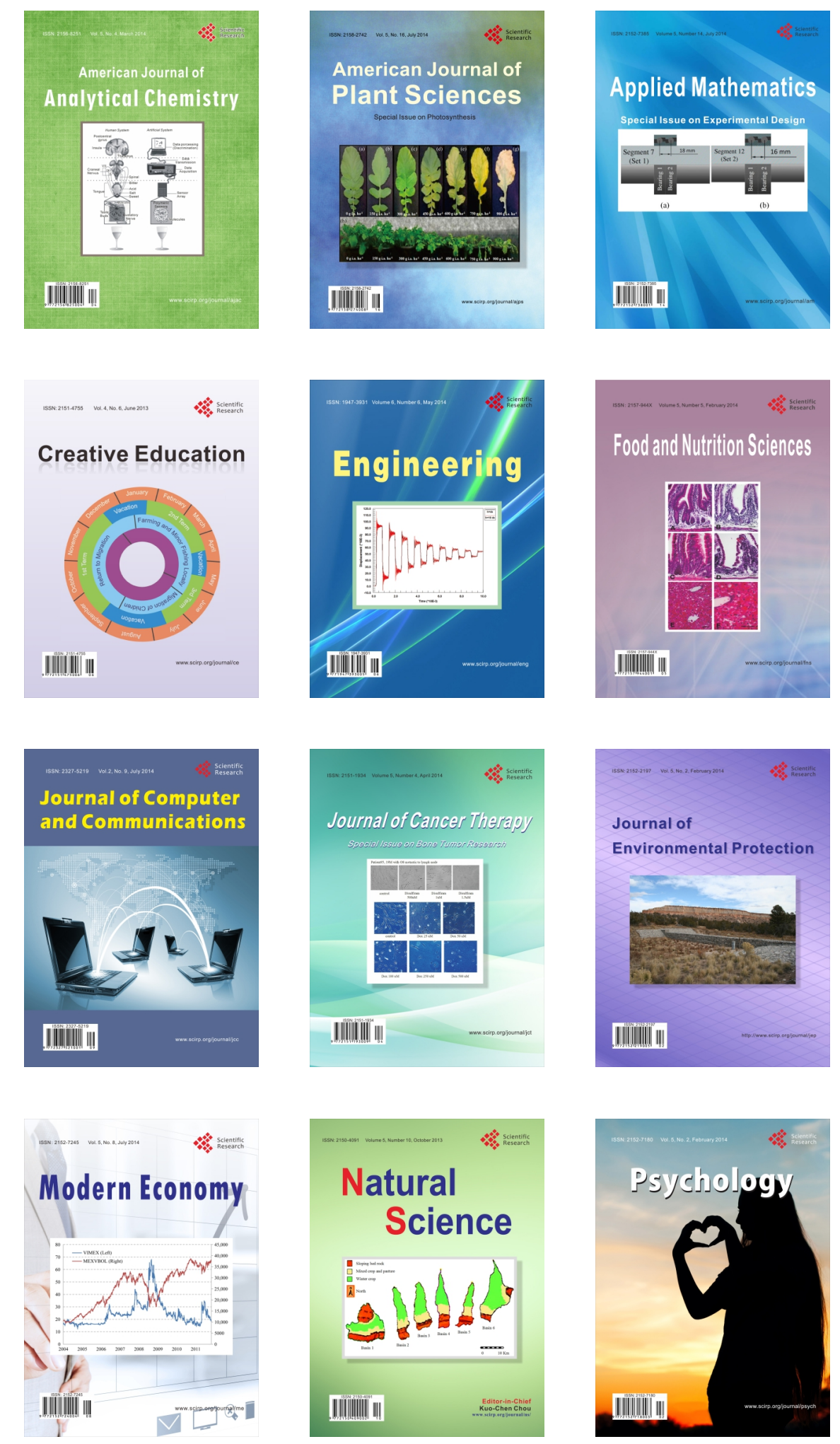